\title{
Calciphylaxis in peritoneal dialysis patients: a single center cohort study
}

\section{Yanchen Zhang' \\ Kristin M Corapi \\ Maria Luongo ${ }^{2}$ \\ Ravi Thadhani ${ }^{2}$ \\ Sagar U Nigwekar ${ }^{2}$}

'Harvard Summer Research Program in Kidney Medicine, Boston, MA, USA; ${ }^{2}$ Division of Nephrology, Massachusetts General Hospital, Boston, MA, USA
Correspondence: Sagar U Nigwekar Division of Nephrology, Massachusetts General Hospital, 165 Cambridge Street, Suite 302, Boston, MA 02114, USA

$\mathrm{Tel}+\mathrm{I} 6177267872$

Fax + I617724 II22

Email snigwekar@mgh.harvard.edu
This article was published in the following Dove Press journal: International Journal of Nephrology and Renovascular Disease 19 September 2016

Number of times this article has been viewed

Background: Calciphylaxis is a rare but devastating condition in end-stage renal disease (ESRD) patients. Most research in the field of calciphylaxis is focused on hemodialysis (HD) patients; however, data on calciphylaxis incidence, risk factors, and mortality in peritoneal dialysis (PD) patients are limited.

Methods: In this cohort study, we examined data from adult patients who initiated PD for ESRD management at our institute's PD unit from January 2001 to December 2015. Associations with the development of calciphylaxis were examined for clinical, laboratory, and medication exposures. Incidence of calciphylaxis and mortality in PD patients who developed calciphylaxis were analyzed. Treatments administered to treat calciphylaxis in PD patients were summarized. Results: In this cohort of 63 patients, 7 patients developed calciphylaxis (incidence rate: 9.0 per 1,000 patient-years). Median age of PD patients who developed calciphylaxis was 50 years, $57 \%$ were white, $71 \%$ females, and $71 \%$ were previously on HD. Female sex, obesity, HD as a prior dialysis modality, recurrent hypotension, elevated time-averaged serum phosphorous levels, reduced time-averaged serum albumin levels, and warfarin therapy were associated with increased calciphylaxis risk in univariate logistic regression analyses. Intravenous sodium thiosulfate was administered in $57 \%$ of PD patients who developed calciphylaxis. One-year mortality in PD patients who developed calciphylaxis was $71 \%$ despite multimodal treatment including sodium thiosulfate, hyperbaric oxygen, cinacalcet, and wound debridement.

Conclusion: Calciphylaxis is a rare but frequently fatal condition in PD patients. Our study provides critical early insights into calciphylaxis incidence, risk factors, and prognosis in PD patients. Sample size and characteristics of patients included in our study limit generalizability to overall PD population and warrant examination in larger independent studies.

Keywords: calcific uremic arteriolopathy, dialysis, hypotension, warfarin

\section{Introduction}

Calciphylaxis also known as calcific uremic arteriolopathy is a highly fatal condition characterized by dermal arteriolar calcification and thrombosis. ${ }^{1}$ Calciphylaxis is predominantly seen in patients with end-stage renal disease (ESRD) and it remains an enigmatic disorder with obscure pathogenesis. ${ }^{2}$

Recent reports describing epidemiology, clinical characteristics, and treatments for calciphylaxis have focused largely on hemodialysis (HD) patients. These data suggest that the incidence of calciphylaxis in HD patients is approximately 3.5 cases per 1,000 patient-years and it may be on the rise. ${ }^{3,4}$ Diabetes mellitus, obesity, abnormalities in mineral bone parameters, and warfarin therapy have been described as calciphylaxis risk factors for HD patients. ${ }^{3,5-7}$ Cinacalcet has been reported to reduce the risk 
of calciphylaxis in HD patients and intravenous sodium thiosulfate has been described to be associated with clinical improvement of calciphylaxis in HD patients. ${ }^{8-11}$ However, corresponding data regarding epidemiology, clinical characteristics, and treatments for calciphylaxis in peritoneal dialysis (PD) patients are limited despite an earlier suggestion that PD patients may be at a higher risk for calciphylaxis compared to HD patients. ${ }^{12,13}$ Understanding the risk factors and outcomes of calciphylaxis in PD patients is critical to the development of future interventions to prevent and treat calciphylaxis, especially as the reasons for an apparent increase in calciphylaxis risk in PD patients are unclear. Therefore, we undertook the present cohort study to describe calciphylaxis incidence, risk factors, therapies, and mortality in PD patients at our center.

\section{Methods}

Partners Human Research Committee approved this study, the need for patient consent was waived for this minimal risk retrospective study. We retrospectively evaluated medical records of all adult (age $>18$ years) patients who initiated PD for ESRD management at our institute's PD unit during the study period from January 1, 2001 to December 31, 2015. Patients who developed calciphylaxis were identified by applying a previously published algorithm that incorporates natural language processing and by manual chart review. ${ }^{4}$ Diagnosis of calciphylaxis was clinically suspected and had histopathological confirmation in all patients. Data regarding demographics, vital signs, comorbidities, dialysis and ESRDrelated characteristics, medications and mineral bone parameters, and nutritional parameters were abstracted from the medical record. Laboratory data were time-averaged for each patient as follows: for patients who developed calciphylaxis, laboratory data were time-averaged from the PD initiation to the diagnosis of calciphylaxis and for patients who did not develop calciphylaxis, laboratory data were time-averaged from the PD initiation to the last available laboratory data. Serum calcium levels were corrected for albumin. ${ }^{14}$ Data for warfarin and medications administered to manage mineral bone abnormalities were abstracted from the time of PD initiation. In addition for PD patients who developed calciphylaxis, ESRD vintage (time between onset of ESRD and development of calciphylaxis) and PD vintage (time between start of PD and development of calciphylaxis) were computed and data regarding calciphylaxis lesions, treatments administered to treat calciphylaxis, and one-year mortality were summarized. A single investigator conducted data abstractions and another investigator independently confirmed data accuracy.

Median with interquartile range (IQR) and frequency percentages were reported for continuous and categorical variables, respectively. We calculated calciphylaxis incidence rate per 1,000 patient-years by assuming it follows a Poisson distribution and applying the following equation: calciphylaxis incidence $=$ (number of new calciphylaxis cases $) \div$ (sum of person-follow-up time at risk). Categorical variables were compared between patients with and without calciphylaxis using a Fisher's exact test and continuous variables were compared using a Mann-Whitney $U$ test. Univariate logistic regression models were applied to compute odds ratio (OR) and $95 \%$ confidence intervals $(\mathrm{CI})$ to test the association between risk factors and calciphylaxis development.

Analyses were performed using SAS, version 9.4. Statistical significance was set at $P<0.05$.

\section{Results}

\section{Incidence and characteristics of PD patients who developed calciphylaxis}

Our cohort comprised of 63 adult PD patients. During the study period, we identified seven patients who developed calciphylaxis tendering calciphylaxis incidence of 9.0 per 1,000 patient-years in PD patients.

Characteristics of individual PD patients who developed calciphylaxis are tabulated in Table 1. Median age was 50 years (IQR: $34-59$ ), 57\% were white, $71 \%$ females, and $43 \%$ had diabetes mellitus. Median body mass index was $31.3 \mathrm{~kg} / \mathrm{m}^{2}$ (IQR: 23.7-32.8), median ESRD vintage was 5.2 years (IQR: 4.1-14.3), and median PD vintage was 4.1 years (IQR: $3.2-7.0)$. Most patients (71\%) were previously on HD and were transitioned to PD for access failure or for inability to tolerate HD. Recurrent episodes of severe hypotension (systolic blood pressure $<80 \mathrm{mmHg}$ ) preceding calciphylaxis were recorded in $43 \%$ and $67 \%$ of patients who had recurrent severe hypotension were previously on HD. None of the PD patients who developed calciphylaxis were on automated PD and all of them were on $2.5 \mathrm{mEq} / \mathrm{L}$ calcium dialysate. Although no patient had residual urine output at the time of calciphylaxis diagnosis, $86 \%$ had weekly $\mathrm{Kt} /$ Vurea at the recommended goal of $\geq 1.70 .{ }^{15}$ Median levels of time-averaged mineral metabolism parameters were as follows - albumin-corrected serum calcium: $9.8 \mathrm{mg} / \mathrm{dL}$ (IQR: 7.9-10.8), phosphorous: $6.1 \mathrm{mg} / \mathrm{dL}$ (IQR: 4.8-6.9), and intact parathyroid hormone: $270 \mathrm{pg} / \mathrm{mL}$ (IQR: 213-657). Median levels of time-averaged nutritional parameters were as follows - serum albumin: $3.1 \mathrm{~g} / \mathrm{dL}$ (IQR: 2.6-3.2) and normalized protein catabolic rate: $0.78 \mathrm{~g} / \mathrm{kg} /$ day (IQR: $0.67-0.83$ ). At the time of PD initiation, $71 \%$ of PD patients who subsequently developed calciphylaxis were on warfarin, $86 \%$ on active vitamin D, $29 \%$ on calcium-based phosphate binder, 
Table I Characteristics of PD patients who developed calciphylaxis

\begin{tabular}{|c|c|c|c|c|c|c|c|}
\hline Characteristic & Patient \# I & Patient \#2 & Patient \#3 & Patient \#4 & Patient \#5 & Patient \#6 & Patient \#7 \\
\hline Age, years & 50 & 41 & 34 & 59 & 65 & 57 & 30 \\
\hline Sex & Female & Female & Male & Female & Female & Male & Female \\
\hline Race & White & Black & White & Black & White & Black & White \\
\hline Etiology of ESRD & Oligonephronia & Lupus & Lupus & Unknown & Diabetes & Diabetes & Primary FSGS \\
\hline Diabetes mellitus & Yes & No & No & No & Yes & Yes & No \\
\hline Body mass index, $\mathrm{kg} / \mathrm{m}^{2}$ & 27.0 & 31.3 & 20.0 & 32.0 & 32.9 & 23.7 & 32.8 \\
\hline $\begin{array}{l}\text { Recurrent severe hypotension } \\
(\mathrm{SBP}<80 \mathrm{mmHg})\end{array}$ & Yes & No & No & Yes & Yes & No & No \\
\hline ESRD vintage, years & 32.0 & 14.3 & 4.I & 5.2 & 4.8 & 5.3 & 3.2 \\
\hline Prior HD therapy & Yes & Yes & Yes & Yes & No & Yes & No \\
\hline PD vintage, years & 8.0 & 7.0 & 3.4 & 4. 1 & 4.8 & 2.1 & 3.2 \\
\hline Weekly Kt/Vurea & 1.98 & 2.12 & I.6I & 1.99 & 2.06 & 2.02 & 2.71 \\
\hline Serum calcium, mg/dL & 9.8 & 9.3 & 7.0 & 10.8 & 10.3 & 10.9 & 7.9 \\
\hline Serum phosphorous, mg/dL & 6.3 & 5.7 & 6.9 & 4.8 & 7.2 & 6.1 & 3.6 \\
\hline Serum intact PTH, pg/mL & 213 & 657 & 89 & 234 & 270 & 678 & 543 \\
\hline Serum albumin, g/dL & 2.2 & 2.8 & 3.2 & 4.1 & 3.1 & 2.6 & 3.2 \\
\hline Normalized protein catabolic rate, $\mathrm{g} / \mathrm{kg} / \mathrm{day}$ & 0.81 & 0.67 & 0.83 & 0.67 & 0.87 & 0.78 & 0.75 \\
\hline Warfarin therapy & Yes & Yes & No & Yes & No & Yes & Yes \\
\hline Active vitamin $D$ agent therapy & Yes & Yes & Yes & Yes & No & Yes & Yes \\
\hline Calcium-based phosphate binder therapy & No & No & Yes & No & No & No & Yes \\
\hline Cinacalcet therapy & No & Yes & No & No & No & Yes & No \\
\hline Location(s) of calciphylaxis lesion(s) & Bilateral toes & Calf, foot & Shin & Thigh & $\begin{array}{l}\text { Thigh, } \\
\text { abdomen }\end{array}$ & Penis & $\begin{array}{l}\text { Bilateral thighs, } \\
\text { forearms }\end{array}$ \\
\hline $\begin{array}{l}\text { Vital status I year after calciphylaxis } \\
\text { diagnosis }\end{array}$ & Dead & Alive & Dead & Dead & Dead & Dead & Alive \\
\hline
\end{tabular}

Note: "Serum calcium levels are corrected for serum albumin levels.

Abbreviations: ESRD, end-stage renal disease, FSGS, focal segmental glomerulosclerosis; HD, hemodialysis; PD, peritoneal dialysis; PTH, parathyroid hormone; SBP, systolic blood pressure.

and $29 \%$ were on cinacalcet. The indications for warfarin therapy for PD patients who developed calciphylaxis included atrial fibrillation $(n=3,60 \%)$ and venous thromboembolic disease from antiphospholipid antibody syndrome $(n=2,40 \%)$.

The number of calciphylaxis skin lesion(s) for each patient ranged from 1 to 6 . Lesions exhibited both proximal and distal distributions but none involved the site of PD catheter insertion. At the time of calciphylaxis diagnosis, all skin lesions were ulcerated and had a black eschar characteristic of calciphylaxis as illustrated in Figure 1.

\section{Risk factors for calciphylaxis in PD patients}

As summarized in Table 2, PD patients who developed calciphylaxis were more likely to be female ( $71 \%$ vs $30 \%$, $P=0.032)$ and had higher frequencies of obesity ( $57 \%$ vs $20 \%, P=0.031)$, prior history of being on $\mathrm{HD}(71 \%$ vs $30 \%$, $P=0.032)$, prior episodes of recurrent hypotension $(43 \%$ vs $7 \%, P=0.004)$, and warfarin therapy exposure ( $71 \%$ vs $16 \%, P=0.001)$. Review of echocardiographic data from calciphylaxis PD patients with recurrent episodes of hypotension showed that all of these patients had symmetric left ventricular hypertrophy and reduced left ventricular ejection fraction (range: 20-32\%). Calciphylaxis patients had

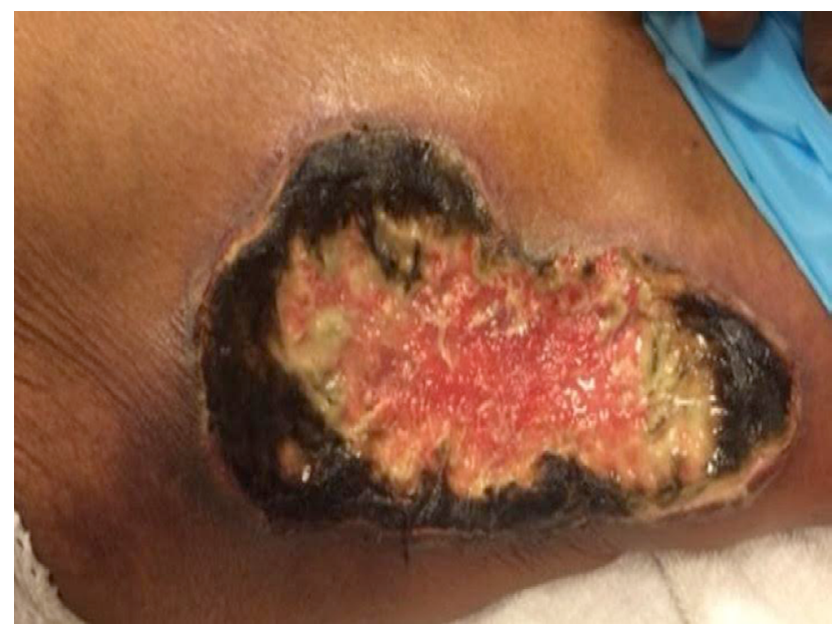

Figure I A representative image showing an ulcerated calciphylaxis lesion with black eschar in a peritoneal dialysis patient.

higher time-averaged serum phosphorous levels and lower time-averaged serum albumin levels. Other characteristics were comparable between PD patients with and without calciphylaxis development.

Results of the univariate logistic regression analyses which focused on covariates with statistically significant differences between PD patients with and without calciphylaxis development are listed in Table 3. Among all the covariates with statistically significant association with calciphylaxis 
Table 2 Comparison of characteristics between PD patients who developed calciphylaxis and PD patients who did not develop calciphylaxis

\begin{tabular}{|c|c|c|c|}
\hline Characteristic & $\begin{array}{l}\text { Calciphylaxis } \\
(n=7)\end{array}$ & $\begin{array}{l}\text { No calciphylaxis } \\
(n=56)\end{array}$ & $P$-value \\
\hline Age, years & 50 (IQR: 34-59) & 54 (IQR: 39-70) & 0.941 \\
\hline Female sex,\% & 71 & 30 & 0.032 \\
\hline White race, \% & 57 & 63 & 0.621 \\
\hline Diabetes mellitus, \% & 43 & 41 & 0.881 \\
\hline Obesity, \% & 57 & 20 & 0.031 \\
\hline Recurrent severe hypotension, \% & 43 & 7 & 0.004 \\
\hline Prior HD therapy, $\%$ & 71 & 30 & 0.032 \\
\hline Weekly Kt/Vurea & 2.02 (IQR: I.98-2.12) & 2.10 (IQR: I.89-2.35) & 0.781 \\
\hline Serum calcium, mg/dL" & 9.8 (IQR: 7.9-10.8) & 9.0 (IQR: 8.5-I0.I) & 0.563 \\
\hline Serum phosphorous, mg/dL & 6.I (IQR: 4.8-6.9) & 3.2 (IQR: 2.2-3.9) & 0.023 \\
\hline Serum intact PTH, pg/mL & 270 (IQR: 2 I3-657) & 29I (IQR: I82-452) & 0.601 \\
\hline Serum albumin, g/dL & 3.I (IQR: 2.6-3.2) & 3.7 (IQR: 3.6-4.6) & 0.049 \\
\hline Normalized protein catabolic rate, $\mathrm{g} / \mathrm{kg} /$ day & 0.78 (IQR: 0.67-0.83) & I.0I (IQR: 0.80-I.06) & 0.092 \\
\hline Warfarin therapy, \% & 71 & 16 & 0.001 \\
\hline Active vitamin D agent therapy, \% & 86 & 49 & 0.821 \\
\hline Calcium-based phosphate binder therapy, \% & 29 & 33 & 0.512 \\
\hline Cinacalcet therapy, \% & 29 & 30 & 0.672 \\
\hline
\end{tabular}

Note: "Serum calcium levels are corrected for serum albumin levels.

Abbreviations: HD, hemodialysis; IQR, interquartile range; PD, peritoneal dialysis; PTH, parathyroid hormone.

Table 3 Results from univariate logistic regression analyses showing risk associations with statistical significance for calciphylaxis development in PD patients

\begin{tabular}{lll}
\hline Covariate & OR & $\mathbf{9 5 \% ~ C l ~}$ \\
\hline Female sex & 5.74 & $1.0 \mathrm{I}-32.54$ \\
Obesity & 5.45 & $1.06-27.99$ \\
Recurrent severe hypotension & 9.75 & $1.60-59.56$ \\
Prior HD therapy & 5.74 & $1.01-32.54$ \\
Serum phosphorous (per I mg/dL increase) & 2.13 & $1.01-4.56$ \\
Serum albumin (per I g/dL reduction) & 2.21 & $1.02-3.65$ \\
Warfarin therapy & 13.06 & $2.18-78.05$ \\
\hline
\end{tabular}

Abbreviations: $\mathrm{Cl}$, confidence intervals; $\mathrm{HD}$, hemodialysis; $\mathrm{PD}$, peritoneal dialysis; OR, odds ratio.

risk, warfarin therapy was associated with the highest risk for calciphylaxis (OR: 13.06, 95\% CI: 2.18-78.05).

\section{Calciphylaxis treatments and mortality in PD patients}

All PD patients who developed calciphylaxis underwent dressing changes and chemical debridement, and received opiate analgesics and nutrition consultations as shown in Figure 2. Surgical debridement was conducted in 43\%, 57\% received hyperbaric oxygen, and $43 \%$ were transitioned to HD. Intravenous sodium thiosulfate was administered in 57\% patients including in patients who did not transition from PD to HD; none received intraperitoneal or intralesional sodium thiosulfate. Intravenous sodium thiosulfate was administered in our PD unit either through peripheral or central venous access. All patients who received intravenous sodium thiosulfate received it as $25 \mathrm{~g}$ (mixed in $100 \mathrm{~mL}$ of normal saline to be infused over 2 hours) 3 times a week. Median duration of intravenous sodium thiosulfate treatment was 3.0 months (IQR: 2.8-5.1). Among the four patients who were treated with intravenous sodium thiosulfate, one reported nausea and vomiting. There were no other side effects recorded from intravenous sodium thiosulfate use. Serum bicarbonate levels in four patients who received intravenous sodium thiosulfate were reduced by an average of $3.5 \mathrm{mEq} / \mathrm{L}$ during intravenous sodium thiosulfate therapy.

One-year mortality in PD patients who developed calciphylaxis was $71 \%$; all deaths were due to sepsis. One-year mortality rate was $67 \%$ in patients who underwent surgical debridement, $50 \%$ in patients who received hyperbaric oxygen, $75 \%$ in patients treated with intravenous sodium thiosulfate, and $100 \%$ in patients who transitioned from PD to HD.

\section{Discussion}

Despite first descriptions of calciphylaxis over 5 decades ago, little is known regarding its epidemiology and risk factors in PD patients. ${ }^{1,13,16,17}$ Our study was designed to address this knowledge gap. In our single center cohort of 63 PD patients, 7 patients developed calciphylaxis during the 15 -year study follow-up period. We noted a number of potential risk factors for calciphylaxis in PD patients. One-year mortality in PD patients who developed calciphylaxis was $71 \%$ despite multimodal treatment. 


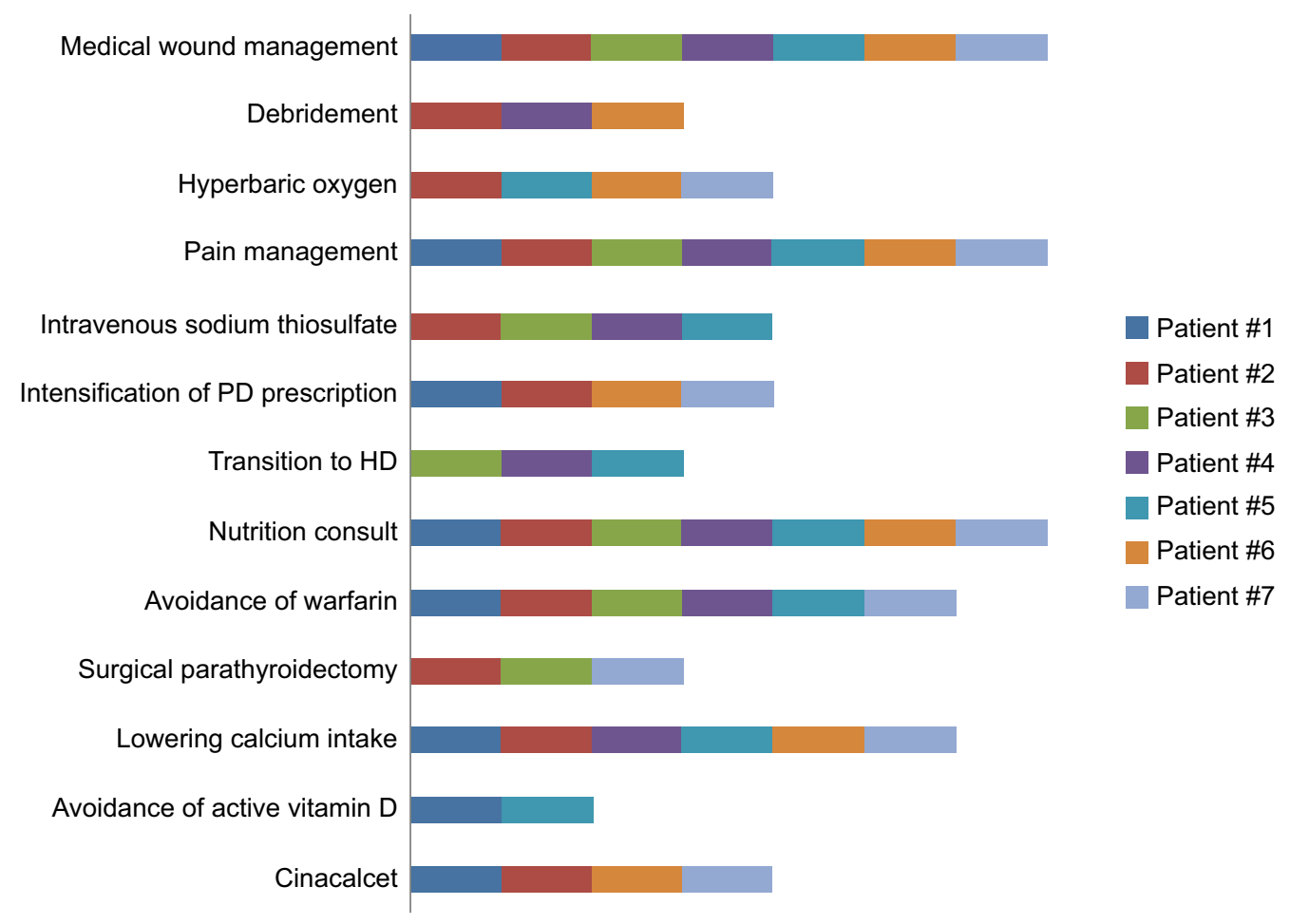

Figure 2 Components of multimodal treatment administered to PD patients who developed calciphylaxis.

Abbreviations: PD, peritoneal dialysis; $\mathrm{HD}$, hemodialysis.

Calciphylaxis incidence rate of 9.0 per 1,000 patientyears in our PD cohort is higher than the recently reported calciphylaxis incidence in HD patients of 3.5 cases per 1,000 patient-years. ${ }^{4,9,18}$ Considering the sample size limitation of our study and single center experience, definitive conclusions regarding comparative effectiveness of PD vs HD for calciphylaxis risk cannot be made; however, our study adds to the debate in the literature regarding whether $\mathrm{PD}$ as a dialysis modality confers a higher calciphylaxis risk than HD. ${ }^{12,13,19}$ It is important to note that although PD was the dialysis modality for our study patients when calciphylaxis was diagnosed, many patients were previously on HD and required transition to PD for access failure or recurrent hypotension. In that regard, these were likely "the sickest of the sick" ESRD patients and our findings may not be generalizable to the overall $\mathrm{PD}$ population. Change in dialysis modality per se has been described to be associated with worse outcomes such as mortality. ${ }^{20}$ Furthermore, prevalence of well-described calciphylaxis risk factors such as warfarin therapy and obesity was higher in PD patients who developed calciphylaxis compared to previously published prevalence of these risk factors in HD patients who developed calciphylaxis., ${ }^{3,5-7,18}$ Thus, it is possible that it is these risk factors and not dialysis modality that dictates calciphylaxis risk. Previous studies have shown that PD is associated with more abnormalities in phosphorous and albumin than $\mathrm{HD}$, especially once residual renal function has deteriorated. ${ }^{21,22}$ Thus, it is possible that our data suggest that those PD patients who have difficulty controlling phosphorus or maintaining their albumin may be at increased risk of calciphylaxis.

The potential risk associations observed in our study may be instructive to understand calciphylaxis pathobiology. Warfarin (vitamin $\mathrm{K}$ antagonist) as a potential risk factor suggests a critical role of vitamin K-dependent proteins such as MGP in the inhibition of vascular calcification. ${ }^{23}$ Recurrent episodes of hypotension preceding calciphylaxis development may point toward reduced perfusion serving as a trigger for ischemia in dermal beds with calcified arterioles. Low normalized protein catabolic rate and serum albumin in PD patients who developed calciphylaxis may implicate that the malnutrition-inflammation complex is at play. ${ }^{24,25}$

It is likely that in our study, a statistically significant difference between PD patients with and without calciphylaxis was not noted due to limited sample size and one-time assessment (at PD initiation) of certain covariates such as medications. This is particularly important as the pathogenesis of calciphylaxis is likely multifactorial, as supported by larger studies ${ }^{3,6}$ in the HD population that noted multiple calciphylaxis risk factors, including diabetes mellitus and advanced age. Small sample size also limited us from conducting multivariable adjusted analyses to examine whether associations observed in univariate analyses 
remain consistent when adjusted for other covariates. Larger studies are needed to ascertain calciphylaxis risk in PD vs HD patients and to confirm risk associations observed in our study. These future studies should be multicenter to improve generalizability, should include assessments of novel dynamics such as recurrent hypotension, echocardiographic parameters, and PD technique (eg, automated PD vs continuous ambulatory PD), and should investigate longitudinal effects of residual kidney function and medications. Given the mortality associated with calciphylaxis, identifying patient and modality characteristics that may confer increased risk is important when helping patients choose a dialysis modality.

In our study, PD patients who developed calciphylaxis received multimodal treatment. Although successful calciphylaxis improvement has been reported with such multimodal treatment, our patients had a high mortality rate. $^{26-28}$ This could be reflective of high mortality due to ulcerated calciphylaxis lesions and/or the overall poor prognosis in patients with recurrent hypotension. Alternative methods of sodium thiosulfate administration were not applied in our study patients, considering the potential risk of further ulceration (with intralesional) and concern for chemical peritonitis (with intraperitoneal). ${ }^{29-32}$

In conclusion, calciphylaxis is a rare but fatal complication in PD patients. Our study provides insights into calciphylaxis epidemiology and risk factors in PD patients and motivates future investigation.

\section{Acknowledgments}

Sagar U Nigwekar is supported by American Heart Association's NCRP Winter 2015 Fellow-to-Faculty Transition Award (15FTF25980003) and by KL2/Catalyst Medical Research Investigator Training award (an appointed KL2 award) from Harvard Catalyst | The Harvard Clinical and Translational Science Center (National Center for Research Resources and the National Center for Advancing Translational Sciences, National Institutes of Health Award KL2 TR001100). The content is solely the responsibility of the authors and does not necessarily represent the official views of Harvard Catalyst, Harvard University, and its affiliated academic healthcare centers, or the National Institutes of Health. This work also received support from National Kidney Foundation's Young Investigator Award, Fund for Medical Discovery Award from Massachusetts General Hospital's Executive Committee on Research (R00000000007190), American Heart Association's NCRP Summer 2014 Mentored Clinical and Population Research Award (15CRP22900008) to Sagar U Nigwekar.
Ravi I Thadhani is supported by National Institute of Health grants DK094872 and DK094486.

Preliminary findings of this manuscript were presented as poster abstracts at the $35^{\text {th }}$ Annual Dialysis Conference in New Orleans, LA, on February 1, 2014 and at the American Society of Nephrology Kidney Week in Atlanta, GA, on November 9, 2013.

The authors would like to thank all the members of Massachusetts General Hospital's PD program and the Massachusetts General Hospital's Multi-disciplinary Calciphylaxis Team for their exceptional dedication to patient care.

\section{Disclosure}

The authors declare the following interests: Sagar U Nigwekar reports receiving speaker honorarium from SanofiAventis and has served as a consultant to Ardelyx. Ravi I Thadhani is a consultant to Fresenius Medical Care North America and Celgene, and has received a research grant from Abbott Laboratories. The other authors report no conflicts of interest in this work.

\section{References}

1. Nigwekar SU, Kroshinsky D, Nazarian RM, et al. Calciphylaxis: risk factors, diagnosis, and treatment. Am J Kidney Dis. 2015;66(1):133-146.

2. Brandenburg VM, Cozzolino M, Ketteler M. Calciphylaxis: a still unmet challenge. J Nephrol. 2011;24(2):142-148.

3. Nigwekar SU, Zhao S, Wenger J, Hymes JL, Maddux FW, Thadhani RI, Chan KE. A Nationally Representative Study of Calcific Uremic Arteriolopathy Risk Factors. J Am Soc Nephrol. Epub 2016 Apr 14.

4. Nigwekar SU, Solid CA, Ankers E, et al. Quantifying a rare disease in administrative data: the example of calciphylaxis. J Gen Intern Med. 2014;29 Suppl 3:724-731.

5. Hayashi M, Takamatsu I, Kanno Y, et al. A case-control study of calciphylaxis in Japanese end-stage renal disease patients. Nephrol Dial Transplant. 2012;27(4):1580-1584.

6. Nigwekar SU, Bhan I, Turchin A, et al. Statin use and calcific uremic arteriolopathy: a matched case-control study. Am J Nephrol. 2013;37(4): 325-332.

7. Galloway PA, El-Damanawi R, Bardsley V, Pritchard NR, Fry AC, Ojha SK, Hiemstra TF. Vitamin K antagonists predispose to calciphylaxis in patients with end-stage renal disease. Nephron. 2015;129(3):197-201.

8. Nigwekar SU, Brunelli SM, Meade D, Wang W, Hymes J, Lacson E Jr. Sodium thiosulfate therapy for calcific uremic arteriolopathy. Clin J Am Soc Nephrol. 2013;8(7):1162-1170.

9. Floege J, Kubo Y, Floege A, Chertow GM, Parfrey PS. The Effect of Cinacalcet on Calcific Uremic Arteriolopathy Events in Patients Receiving Hemodialysis: The EVOLVE Trial. Clin J Am Soc Nephrol. 2015;10(5):800-807.

10. Noureddine L, Landis M, Patel N, Moe SM. Efficacy of sodium thiosulfate for the treatment for calciphylaxis. Clin Nephrol. 2011;75(6): 485-490.

11. Zitt E, Konig M, Vychytil A, et al. Use of sodium thiosulphate in a multi-interventional setting for the treatment of calciphylaxis in dialysis patients. Nephrol Dial Transplant. 2013;28(5):1232-1240.

12. Fine A, Zacharias J. Calciphylaxis is usually non-ulcerating: risk factors, outcome and therapy. Kidney Int. 2002;61(6):2210-2217.

13. New N, Mohandas J, John GT, et al. Calcific uremic arteriolopathy in peritoneal dialysis populations. Int J Nephrol. 2011;2011:982854. 
14. Payne RB, Little AJ, Williams RB, Milner JR. Interpretation of serum calcium in patients with abnormal serum proteins. Br Med J. 1973; 4(5893):643-646.

15. Lo WK, Bargman JM, Burkart J, et al. Guideline on targets for solute and fluid removal in adult patients on chronic peritoneal dialysis. Perit Dial Int. 2006;26(5):520-522.

16. Rees JK, Coles GA. Calciphylaxis in man. Br Med J. 1969;2(5658): 670-672.

17. Brandenburg VM, Cozzolino M, Mazzaferro S. Calcific uremic arteriolopathy: a call for action. Semin Nephrol. 2014;34(6):641-647.

18. Brandenburg VM, Kramann R, Rothe H, et al. Calcific uraemic arteriolopathy (calciphylaxis): data from a large nationwide registry. Nephrol Dial Transplant. Epub 2016 Jan 29.

19. Fine A, Fontaine B. Calciphylaxis: the beginning of the end? Perit Dial Int. 2008;28(3):268-270.

20. McDonald SP, Marshall MR, Johnson DW, Polkinghorne KR. Relationship between dialysis modality and mortality. J Am Soc Nephrol. 2009;20(1):155-163.

21. Wang AY, Woo J, Wang M, Sea MM, Sanderson JE, Lui SF, Li PK. Important differentiation of factors that predict outcome in peritoneal dialysis patients with different degrees of residual renal function. Nephrol Dial Transplant. 2005;20(2):396-403.

22. Cupisti A, Gallieni M, Rizzo MA, Caria S, Meola M, Bolasco P. Phosphate control in dialysis. Int J Nephrol Renovasc Dis. 2013;6: 193-205.
23. Danziger J. Vitamin K-dependent proteins, warfarin, and vascular calcification. Clin J Am Soc Nephrol. 2008;3(5):1504-1510.

24. Kalantar-Zadeh K, Ikizler TA, Block G, Avram MM, Kopple JD. Malnutrition-inflammation complex syndrome in dialysis patients: causes and consequences. Am J Kidney Dis. 2003;42(5):864-881.

25. Wilmer WA, Magro CM. Calciphylaxis: emerging concepts in prevention, diagnosis, and treatment. Semin Dial. 2002;15(3):172-186.

26. Baldwin C, Farah M, Leung M, Taylor P, Werb R, Kiaii M, Levin A. Multi-intervention management of calciphylaxis: a report of 7 cases. Am J Kidney Dis. 2011;58(6):988-991.

27. Nigwekar SU. Multidisciplinary approach to calcific uremic arteriolopathy. Curr Opin Nephrol Hypertens. 2015;24(6):531-537.

28. Brucculeri M, Haydon AH. Calciphylaxis presenting in early chronic kidney disease with mixed hyperparathyroidism. Int J Nephrol Renovasc Dis. 2011;4:157-160.

29. Strazzula L, Nigwekar SU, Steele D, et al. Intralesional sodium thiosulfate for the treatment of calciphylaxis. JAMA Dermatol. 2013;149(8): 946-949.

30. Gupta DR, Sangha H, Khanna R. Chemical peritonitis after intraperitoneal sodium thiosulfate. Perit Dial Int. 2012;32(2):220-222.

31. Mataic D, Bastani B. Intraperitoneal sodium thiosulfate for the treatment of calciphylaxis. Ren Fail. 2006;28(4):361-363.

32. Dethloff SB. Calcific uremic arteriolopathy: treatment with intraperitoneal sodium thiosulfate in a patient on peritoneal dialysis. Nephrol Nurs J. 2012;39(4):323-325, 347.

\section{Publish your work in this journal}

The International Journal of Nephrology and Renovascular Disease is an international, peer-reviewed open access journal focusing on the pathophysiology of the kidney and vascular supply. Epidemiology, screening, diagnosis, and treatment interventions are covered as well as basic science, biochemical and immunological studies. The manuscript management system is completely online and includes a very quick and fair peer-review system, which is all easy to use. Visit http://www. dovepress.com/testimonials.php to read real quotes from published authors. 